\title{
Fracture behavior of additively manufactured acrylonitrile butadiene styrene (ABS) materials
}

\author{
Kevin R. Hart and Eric D. Wetzel ${ }^{*}$ \\ U.S. Army Research Laboratory, Materials and Manufacturing Sciences Division \\ Aberdeen Proving Ground, MD 21005 \\ * Corresponding Author: eric.d.wetzel2.civ@ mail.mil, 410-306-0851
}

For submission to:

Engineering Fracture Mechanics

2 February 2017

\begin{abstract}
The effect of layer orientation on the fracture properties of poly(acrylonitrile-butadiene-styrene) (ABS) materials fabricated through the fused filament fabrication (FFF) process was explored. Critical elasticplastic strain energy release rates of single edge notch bend (SENB) specimens with variable cracktip/laminae orientations were compared. Results show that the inter-laminar fracture toughness (fracture between layers) is approximately one order of magnitude lower than the cross-laminar toughness (fracture through layers) of similarly manufactured parts. Contrasting brittle and ductile fracture behavior is observed for inter-laminar and cross-laminar crack propagation, respectively, demonstrating that the elastic-plastic response of AM ABS parts is governed by the direction of crack propagation within the laminated structure. Fracture surfaces of failed specimens are examined using scanning electron microscopy to show micro- and macro-scale toughening/embrittling mechanisms. Techniques for designing tougher additively manufactured materials based on biological analogies are discussed.
\end{abstract}




\section{Introduction}

Additive manufacturing (AM) has revolutionized the creation of three-dimensional solid objects by enabling inexpensive and rapid conversion of computer-generated models into physical parts [1] . For AM fabrication of polymers, the most commonly used technology is fused filament fabrication (FFF), wherein thermoplastic polymer filament is fed to a heated nozzle, melted, and subsequently deposited layer-by-layer onto a build plate to create a desired three-dimensional geometry. Polymeric parts manufactured using FFF typically exhibit anisotropic, locally orthotropic behavior and have lower elastic moduli, strain to failure, and ultimate strength when compared to parts of the same geometry made through more traditional polymer manufacturing methods such as thermoforming or injection molding [2].

The most widely used and commonly studied polymer for FFF is poly(acrylonitrile-butadienestyrene) (ABS) [3]. ABS is an amorphous, grafted thermoplastic terpolymer containing acrylonitrile (A), styrene (S), and polybutadiene (PB) components. A wide range of ABS structures and properties are possible depending on the ratios of each component and the processing history $[4,5]$. A common and preferable ABS microstructure consists of a continuous and stiff A-S phase with compliant PB particle inclusions between $0.2-50 \mu \mathrm{m}$ in diameter [6]. This microstructure results in a polymer that is both stiff and tough and also gives rise to complex failure mechanisms such as cavitation, crazing, localized shear yielding, and void coalescence [7-9]. In addition, because ABS is inexpensive, amorphous, and processed at relatively low temperatures (ca. $175-275^{\circ} \mathrm{C}$ ), it is well-suited for FFF.

The mechanical properties of FFF structures depend on material, processing, and geometry details [1]. For example, studies have shown that infill density [10] build orientation [11-17] layer thickness [13, 15] raster width [13, 15] air gap [13, 15, 17, 18] and printing temperatures [18, 19] all affect the mechanical properties of AM ABS parts and contribute to the material's orthotropic behavior. Many of these studies have focused on the tensile properties [10-17, 20] although flexural [19], torsional [17], and compression $[21,22]$ behaviors have also been reported. 
In general, materials manufactured using the FFF process have lower moduli, strength, and stiffness when compared to bulk materials of the same geometry. The knockdown in mechanical properties for FFF parts is due to two primary factors: porosity and imperfect weld-lines. Porosity is inherent to existing FFF technologies because parts are built from deposited polymer traces with rounded features that do not stack into perfectly dense ensembles [23]. Long void spaces therefore persist between traces, both within a build plane and between planes. Even when traces make intimate contact, the mechanical strength of their interface is unlikely to be comparable to that of the bulk polymer. This interface is formed by placing molten polymer in contact with previously deposited polymer which has cooled to a lower temperature. For full bonding to take place, a local volume of material within each trace needs to rise to a sufficiently high temperature to enable polymer chains to flow and entangle across the interface [11]. While higher temperatures and lower deposition speeds can enhance such bondforming processes, the same process adjustments lead to poorer geometric control, low surface quality, and longer print times. Therefore current FFF processing requires a compromise between achieving sufficient mechanical properties while maintaining geometric stability.

Surprisingly few studies have investigated the fracture properties of AM parts. Mode I fracture between single raster weld-lines of ABS was investigated using single edge notch tension (SENT) specimens [24]. Authors demonstrated that increased printing temperatures and annealing times led to increased fracture performance. However, results of single weld-line testing are difficult to translate to thick, multi-layered structural components. More recently, fully-dense laser sintered nylon 12 compact tension specimens with varying raster orientations with respect to the crack-tip were fabricated to study mode I fracture and fatigue [25]. Authors confirmed the orthotropic nature of fracture in AM parts by demonstrating that crack arrest was improved when raster orientation was perpendicular to the initial crack-tip. In another study, PLA compact tension specimens with varying raster orientations ahead of the crack-tip were used to study mode I fracture with similar findings [26]. However, no studies on the 
fracture properties of component-scale AM ABS materials have been undertaken and discussion regarding flaw/lamina orientation which optimizes material toughness is lacking.

In this paper, the orthotropic fracture behavior of AM ABS materials is examined through fracture experiments of materials manufactured with variable crack-tip/lamina orientations. Fracture surfaces of failed specimens are examined using scanning electron microscopy to show micro- and macro-scale toughening/embrittling mechanisms. Additionally, we discuss fracture behavior of analogous biological materials such as wood, bone, and nacre, how these materials self-assemble to provide increased fracture resistance, and how engineers designing AM parts may use this information to design tougher AM components.

\section{Fracture theory}

\subsection{Single edge notch bend (SENB) testing}

The National Institute of Standards and Technology recently compiled a list of ASTM and ISO standards applicable for a range of mechanical testing of AM parts [1] . Specifically for evaluation of fracture properties, authors noted that the incorporation of a pre-crack and the development of plastic zone fronts in AM parts would introduce challenges. The authors ultimately advised the use of single edge notch bend (SENB) testing via ISO 13586:2000 [27] (similar to ASTM E1820 [28]) for linearelastic materials and ASTM D6068 [29] for elastic-plastic materials. ASTM D6068 has been used to study fracture in injection molded ABS via SENB testing [30-32].

\subsection{Linear elastic fracture}

For a linear elastic material, the critical mode I stress intensity factor $K_{I c}$ (in units of Pa-m ${ }^{1 / 2}$ ) can be calculated according to ASTM E1820 using

$$
K_{I c}=\left[\frac{P_{c} S}{B W^{3 / 2}}\right] * f\left(a_{c} / W\right)
$$


where $P_{c}$ is the critical load at fracture, $S$ is the span length, $B$ is the sample depth, $W$ is the sample height, $a_{c}$ is the crack length immediately prior to fracture, and the function $f\left(a_{c} / W\right)$ is defined by the geometry of the SENB specimen as

$$
f\left(a_{c} /_{W}\right)=\frac{3\left(\frac{a_{c}}{W}\right)^{1 / 2}\left[1.99-\left(\frac{a_{c}}{W}\right)\left(1-\frac{a_{c}}{W}\right)\left(2.15-3.93\left(\frac{a_{c}}{W}\right)+2.7\left(\frac{a_{c}}{W}\right)^{2}\right)\right]}{2\left(1+2 \frac{a_{c}}{W}\right)\left(1-\frac{a_{c}}{W}\right)^{3 / 2}}
$$

Under the assumption of linear-elastic behavior and straight crack propagation, conversion of critical mode I stress intensity factor, $K_{I c}$ to critical strain energy release rate, $G_{I c}$ (units of $\mathrm{J} / \mathrm{m}^{2}$ ) and subsequently to the critical elastic-plastic strain energy release rate, $J_{I c}$ (units of $\mathrm{J} / \mathrm{m}^{2}$ ) can be accomplished using

$$
J_{I C}=G_{I C}=K_{I C}^{2}\left(\frac{1-v^{2}}{E}\right)
$$

where $E$ is the elastic modulus and ?? is the Poisson's ratio of the material. Conversion of the calculated critical stress intensity factor $\left(K_{I c}\right)$ to the critical elastic-plastic strain energy release rate $\left(J_{I c}\right)$ allows comparison of the fracture properties of a brittle material with the fracture properties of a ductile material as derived from elastic-plastic theory.

\subsection{Elastic-plastic fracture}

Materials that exhibit significant ductility in the vicinity of the crack-tip cannot be analyzed using linear-elastic fracture theory. Instead, the critical elastic-plastic strain energy release rate is calculated using J-integral methods. To apply this theory to SENB testing, ASTM D6068 (the standard test method for determining J-R curves of plastic materials) is utilized in conjunction with ASTM E1820 (the standard test method for measurement of fracture toughness). In this test methodology, a specimen $i$ with an initial

crack length $a_{o}^{(i)}$ is loaded to induce a crack propagation length $\Delta a^{(i)}$, with the resulting load deflection 
curve used to calculate a fracture strain energy $U^{(i)} \cdot J^{(i)}$ values are then calculated for each fracture test according to

$$
J^{(i)}=\frac{\eta U^{(i)}}{B\left(W-a_{o}^{(i)}\right)}
$$

where $\eta$ is a geometric constant (for SENB, $\eta=1.9$ ) $[28,32], B$ is the sample width, and $W$ is the sample height. A $J-R$ curve $\left(f^{f i t}\right)$ for the series of tests is then constructed by plotting $J^{(i)}$ against $\Delta a^{(i)}$ for all samples and fitting a power law of the form

$$
J^{f i t}(\Delta a)=C_{1} \Delta a^{C_{2}}
$$

where $C_{1}$ and $C_{2}$ are fitting parameters. On the same axes, an offset blunting line $\left(J^{\text {blunt }}\right)$ which accounts for sufficient development of the plastic zone in front of the crack-tip is added, defined by

$$
J^{\text {blunt }}(\Delta a)=2 \sigma_{y}(\Delta a-\varepsilon)
$$

where $\sigma_{y}$ is the yield stress of the material and $\varepsilon$ is the blunting offset value, $0.2 \mathrm{~mm}[28,32]$. Once the $J$ $R$ curve and offset blunting lines are constructed, the critical elastic-plastic strain energy release rate, $J_{I c}$, is calculated as the intersection of the two lines.

\section{Experimental}

\subsection{SENB sample fabrication}

SENB specimens measuring $100 \times 20 \times 10 \mathrm{~mm}$ were fabricated using fused filament fabrication (FFF). All specimens were manufactured using a Taz 6 desktop printer (Lulzbot; Loveland, Co) with 1.75 mm ABS M30 filament (Stratasys; Eden Prairie, MN). The nozzle and print bed temperatures were $240{ }^{\circ} \mathrm{C}$ and $115^{\circ} \mathrm{C}$, respectively. Print speed was $50 \mathrm{~mm} / \mathrm{s}$ at a fill density of $100 \%$ and a layer height of $0.22 \mathrm{~mm} /$ layer. CAD models were generated using Solidworks 2014 (Dassault Systems; Waltham, MA) and translated into machine language using Cura 19.12 (open-source) software.

We choose to describe the printed specimens as "laminates", where each laminae is a layer of material parallel to the print bed with a nominal thickness equal to the layer height $(0.22 \mathrm{~mm})$. Each 
laminae is itself composed of individual raster lines whose orientation varies within a layer and between layers. Specimens for inter-laminar fracture testing were constructed with the longest part edge oriented vertically (perpendicular to the build plate). Specimens for cross-laminar fracture testing were constructed with the longest part edge oriented horizontally (parallel to the build plate). Specimens to investigate crack kinking behavior were constructed with the longest edge oriented at an oblique angle of $75^{\circ}$ relative to vertical $\left(15^{\circ}\right.$ incline relative to the build plate). Orientations of vertically, horizontally, and obliquely printed SENB samples with respect to the printer build plate are depicted in Figure 1a.

\subsubsection{Vertically printed SENB specimens}

Vertically printed SENB specimens contained 454 layers, each layer containing predominantly uni-axially oriented raster lines oriented in an alternating $\left[0 / 90^{\circ}\right]$ stacking sequence. Each layer in these vertical specimens, as well as in horizontal and oblique specimens, also has a single outer raster line of material to define the perimeter of each layer, as is standard practice for most FFF builds. A 50- $\mu$ m-thick, adhesive-backed polyimide film was inserted by hand between layers 227 and 228 during printing to serve as the pre-crack notch approximately $10 \mathrm{~mm}$ in length. The use of a polyimide film between printed layers ensured that crack propagation would initiate and continue between layers in the structure during fracture testing. Following the completion of printing, a $1.7 \mathrm{~mm}$ diameter arresting hole was drilled through the sample $5 \mathrm{~mm}$ in front of the pre-crack notch tip using a \#51 drill bit on a milling machine (Model 5410; Sherline Products; Vista, CA) to serve as a crack arrest during fracture testing. Final sample dimensions and laminae orientations of a vertically printed SENB specimen are illustrated in Figure $1 b$.

\subsubsection{Horizontally printed SENB specimens}

Horizontally printed SENB specimens contained 91 layers with an alternating $\left[0 / 90^{\circ}\right]$ stacking sequence throughout. A pre-crack notch was incorporated into the part after completion of the print. 
Using a water cooled diamond saw (Discotom-65; Struers ApS; Ballerup, Denmark), a rough $1.5 \mathrm{~mm}$ wide notch was machined $10 \mathrm{~mm}$ into the long edge to create a fluted region. A fresh razor blade was then inserted into the fluted region and lightly struck with a soft mallet to facilitate the creation of a sharp pre-crack across the width of the sample. Pre-crack and laminae orientations of a horizontally printed SENB specimen are illustrated in Figure 1c.

\subsubsection{Obliquely printed SENB specimens}

Obliquely printed SENB specimens contained 201 layers with an alternating $\left[0 / 90^{\circ}\right]$ stacking sequence throughout. Scaffold material made of ABS M30 (Stratasys Inc.) at an infill density of 25\% was used to support obliquely printed parts and was broken away manually after completion of the FFF process. A pre-crack notch was incorporated into the part after completion of the print. Using a water cooled diamond saw (Struers ApS), a rough $1.5 \mathrm{~mm}$ wide notch was machined $10 \mathrm{~mm}$ into the long edge to create a fluted region. A fresh razor blade was then inserted into the fluted region and lightly struck with a soft mallet to facilitate the creation of a sharp pre-crack across the width of the sample. Pre-crack and laminae orientations of an obliquely printed SENB specimen are illustrated in Figure 1d.

\subsection{SENB testing}

\subsubsection{SENB testing protocol}

Three-point SENB testing was performed on a benchtop load frame (Model 1122; Instron; Canton, MA) with a $4.45 \mathrm{kN}$ capacity load cell. Testing was performed in displacement control at a rate of $1 \mathrm{~mm} / \mathrm{min}$ using Bluehill software (v2.17; Instron). The span length was $80 \mathrm{~mm}$ for all tests. Pins in contact with the specimen measured $6.35 \mathrm{~mm}$ in diameter. Images of the samples during testing were recorded using a monochrome CCD camera (Point Grey Research Inc.; Richmond, BC, Canada) with an affixed $100 \mathrm{~mm}$ zoom lens (AF Nikor; Canon; Tokyo, Japan) at a rate of $1 \mathrm{~Hz}$ during testing. 


\subsubsection{Inter-laminar fracture testing (vertically printed SENB specimens)}

Inter-laminar fracture tests were performed on vertically fabricated SENB specimens. Samples were tested to $0.75 \mathrm{~mm}$ of displacement then unloaded. In all samples, a crack propagated between laminae from the pre-crack notch to the crack arrest hole, with a load-displacement response consistent with brittle behavior. Following testing, samples were fully fractured by hand to expose the original fracture surface. Initial crack length prior to failure $\left(a_{c}\right)$ was measured using optical microscopy by imaging the fracture plane of the sample using a digital microscope (VHX-2000; Keyence Corporation; Osaka, Osaka Prefecture, Japan) with a resolution of $7.2 \mu \mathrm{m} /$ pixel. Assuming the measurement was resolved to within 3 pixels, error of the initial crack length measurement was $21.6 \mu \mathrm{m}$ or approximately $0.2 \%$ of the average initial crack length.

Because of the brittle fracture behavior observed during inter-laminar testing, results were analyzed using linear elastic fracture theory (Eqns. 1-3). To complete the calculations, an elastic modulus $E$ of $2.18 \mathrm{GPa}$ and Poisson's ratio ?? of 0.35 were used [33].

To ensure that the arresting hole $5 \mathrm{~mm}$ in front of the initial pre-crack notch did not interrupt the formation of the plastic zone ahead of the crack, the plastic radius at the crack-tip was approximated using the Barenblatt/Dugdale cohesive zone model [34-36]. In this model, the plastic radius in front of the crack-tip was estimated using

$$
r_{p} \approx \frac{\pi}{8}\left(\frac{K_{I c}}{\sigma_{y}}\right)^{2}
$$

where $r_{p}$ is the plastic radius in front of the crack-tip, $K_{I c}$ is the critical mode I stress intensity factor, and $\sigma_{y}$ is the yield stress of the material (26 MPa [33]). For vertically constructed SENB samples, the plastic radius is approximately $360 \mu \mathrm{m}$. Since the arresting hole is located at a distance of $5 \mathrm{~mm}$ from the initial crack, its presence does not significantly alter the development of the plastic zone or the fracture toughness analysis. 


\subsubsection{Cross-laminar fracture testing (horizontally oriented SENB specimens)}

Cross-laminar fracture tests were performed on horizontally fabricated SENB specimens. Unlike inter-laminar fracture tests, crack propagation in cross-laminar fracture tests was ductile in nature, requiring elastic-plastic fracture analysis (Eqns. 4-6). Each sample $i$ was tested to a pre-defined crosshead displacement $\delta^{(i)}$ ranging from 1 to $2.2 \mathrm{~mm}$, then unloaded. After testing, a freeze fracture was performed to expose the fracture surface; samples were removed from the test frame, submerged in liquid nitrogen for 30 seconds then replaced into the frame and loaded until brittle fracture through the sample occurred. Images of the fracture plane were gathered using a digital microscope (VXH-2000; Keyence Corporation) with a resolution of $7.2 \mu \mathrm{m} /$ pixel. Initial crack length, $a_{o}^{(i)}$, and the total crack propagation length during testing, $\Delta a^{(i)}$, were measured using micrographs of the fracture surface as prescribed by Section 8.6 of ASTM D6068 using ImageJ (v1.50i) software. Assuming the measurement was resolved to within 3 pixels, error of the crack propagation length measurement was consistently $21.6 \mu \mathrm{m}$. At the shortest crack propagation length measured $(\Delta a=0.32 \mathrm{~mm})$, this results in an error of approximately $6.8 \%$, though this error reduces to $1.1 \%$ with the longest crack length reported.

The energy required to extend the crack, $U^{(i)}$, is calculated as the difference between the total energy under the load vs. displacement curve during fracture testing, $U_{T}$, and the indentation energy associated with sample deformation under the loading pins, $U_{\text {ind }}$. Indentation energy was approximately $5 \%$ of the total energy in each test (Section S.1). For the offset blunting line estimation (Eqn. 6), a yield stress value $\sigma_{y}=31 \mathrm{MPa}[33]$ was used.

\subsubsection{Fracture testing of samples with oblique lamina/crack-tip orientations}

Specimens containing laminae traveling at oblique angles with respect to the initial pre-crack were tested to a pre-defined cross-head displacement of $2.0 \mathrm{~mm}$ at a rate of $1.0 \mathrm{~mm} / \mathrm{min}$ then unloaded. While testing, crack kinking was observed, and fracture occurred both between laminae and across 
laminae, preventing rigorous calculation of the critical elastic-plastic strain energy release rate according to the aforementioned ASTM standards. As a result, fracture toughness values of obliquely fabricated SENB specimens are not reported.

\subsection{SEM fractography}

Post-testing scanning electron microscopy (SEM) was employed to characterize the fracture plane morphology of vertically and horizontally manufactured SENB specimens after testing. To prepare, fractured samples were affixed to $25.4 \mathrm{~mm}$ diameter aluminum stubs using carbon tape then sputter coated with gold-palladium for 60 seconds using a sputter coating machine (Desk V HP; Denton Vacuum; Moorestown, NJ). Images were acquired using a Hitachi 4700 SEM under high vacuum at $5.0 \mathrm{kV}$.

\section{Results}

\subsection{Inter-laminar fracture testing}

An image of a vertically manufactured SENB specimen in preparation for inter-laminar SENB fracture testing is depicted in Figure 2a. Laminae oriented parallel to the pre-crack notch and the arresting hole are apparent. Load vs. displacement curves for inter-laminar fracture testing are provided in Figure 2b. Linear-elastic loading behavior, as well as brittle, stick-slip fracture behavior was observed during testing as indicated by large drops in the load at discrete points in the cross-head displacement continuum. One or two large fracture events occurred in each sample as the crack propagated from its original position (Fig. 2c) to its arrested position (Fig. 2d) in less than one second (time between captured frames). Sample to sample variation of the effective stiffness is a result of initial crack lengths varying from approximately $0.45 a / W$ to $0.55 a / W(9$ to $11 \mathrm{~mm}$ ). These stiffness variations have minimal bearing on the results of the fracture analysis if the initial crack length is properly accounted for [37]. Variation of the stiffness within a sample between initial loading and displacement values of approximately 0.05 $\mathrm{mm}$ is a result of the pins fully engaging with the rough surface of the additively manufactured SENB 
sample which creates an artificial hardening during preliminary loading. The effect of this artificial hardening on the fracture analysis is negligible.

The resulting mode I stress intensity factor, $K_{I c}$, and critical elastic-plastic strain energy release rate, $J_{I c}$, for inter-laminar fracture testing were $0.789 \pm 0.131 \mathrm{MPa}-\mathrm{m}^{1 / 2}$ and $256 \pm 84 \mathrm{~J} / \mathrm{m}^{2}$, respectively. These values are comparable to brittle solids such as glass $\left(K_{I c} \approx 0.1-1.0 \mathrm{MPa}-\mathrm{m}^{1 / 2}\right)$ and unreinforced epoxy $\left(\mathrm{K}_{1 \mathrm{c}} \approx 0.3-1.5 \mathrm{MPa}-\mathrm{m}^{1 / 2}\right)$ and are not typical of plastically deformable polymers like bulk ABS.

Images of the fracture plane of one sample after testing is provided in Figure 3. The optical micrograph in Figure 3a depicts clear delineation between the pre-crack region, the crack propagation region, the arresting hole, and post-testing fractured material. Individual raster lines are also identifiable. Figures $3 b$ through $3 d$ are SEM micrographs that depict the morphology of the fractured region. Figure $3 \mathrm{~b}$ depicts the origin of the crack propagation region. On the top half of the image, vertical stripes of approximately $500 \mu \mathrm{m}$ in width are visible. These stripes are lines of fractured material which, before fracturing, were the weld-line interfaces between laminae. Figure $3 \mathrm{c}$ shows one of the fractured weldlines at higher magnification. Tortuosity of the fracture plane is now apparent at this magnification, indicating a tearing-type fracture at the interface, common for ductile materials. Also, we observe regions of un-fractured material on either side of the fractured raster, which is a result of the porosity inherent to most AM parts. As the crack propagates during testing, it seeks the path of least resistance through the plane between laminae that contains the most porosity and the least weld-line overlap. Finally, the microstructure of fractured material is depicted in Figure 3d. At this scale, there is evidence of localized shear yielding as well as micro-porosity resulting from rubber particle cavitation commonly observed during failure of bulk ABS [7-9] . Both shear yielding and cavitation mechanisms are commonly associated with high energy absorbing, ductile fracture.

The ductile features observed via microscopy are surprising given the brittle response of the load displacement curves in Fig. 2b. Brittle loading curves result from materials in which the stress required to initiate fracture exceeds the energy required to propagate the crack so that, once fracture initiates, it 
continues rapidly through the material without additional loading. We hypothesize that the fracture behavior in our specimens is strongly influenced by the significant magnitude and regularity of the porosity in the FFF structures. In areas with high weld-line overlap, energy builds at the crack-tip until crack initiation ensues. After initiation, the crack then moves to the fracture plane of least resistance where porosity is the highest, where it then dynamically propagates through that region because of a lack of material available to re-pin the crack. This means that locally on the micro-scale (as in Figure $3 \mathrm{~d}$ ) the failure appears ductile, while on the macro-scale the load vs. displacement response appears brittle (as in Figure 2b).

\subsection{Cross-laminar fracture testing}

An image of a horizontally manufactured SENB specimen in preparation for cross-laminar fracture testing is depicted in Figure 4a. Laminae oriented perpendicular to the fluted pre-crack region are apparent. Load vs. displacement curves for cross-laminar fracture testing are provided in Figure 4b. Non-linear, elastic-plastic loading behavior as well as ductile, tearing fracture was observed during testing in all samples. Close-up images of the region near the crack-tip at various moments during loading are depicted in Figures 4c-e. As the material is loaded and moves from its pristine state (Fig. 4c) to its fully loaded state (Fig. 4e), whitening of the material in front of the crack-tip occurs. Whitening is a result of crazing in the highly stressed material ahead of the crack-tip and is another confirmation of elastic-plastic response.

The J-R curve for cross-laminar fracture test specimens is provided in Figure 5. Data for each specimen used to construct the J-R curve are provided in Table 1. Deviations of experimental data from the fit are a result of inconsistent sample replication and pre-crack lengths. Error in calculations of $\mathbf{J}$ values also result from variations in width and thickness measurements of each individual sample. These variations amount to a consistent error of approximately $3.1 \%$ for each sample. We note that errors arising from measurement variation within a sample are likely insignificant compared to variations in 
local bonding and packing efficiency typical for an FFF deposition process. However, the calculated mode I critical elastic-plastic strain energy release rate, $J_{I c}$, was $2260 \mathrm{~J} / \mathrm{m}^{2}$.

Images of the fracture surface of a sample tested to $2.0 \mathrm{~mm}$ of displacement are provided in Figure 6. Figure 6a is an annotated optical micrograph of the fracture surface depicting the fluted region made by the rough diamond saw cut, the pre-crack region made by tapping the razor blade, the crack propagation region made during SENB testing, and the post-testing freeze fracture region. Significant whitening in the crack propagation region is a result of crazing in the material in the vicinity of the propagating crack while the sample was loaded. This whitening is absent in the freeze fracture region because the brittle nature of freeze fracturing eliminates crazing which only occurs during elastic-plastic deformation. Initial crack length $\left(a_{o}\right)$ and crack propagation length $(\Delta a)$ measurements used in the calculation of $J$ (Eq. 5), $f^{\text {fit }}$ (Eq. 6), and $J^{\text {blunt }}$ (Eq. 7) were made on optical micrographs such as those depicted in Figure 6a using measurement techniques outlined in ASTM D6068, Section 8.6.

SEM micrographs of the fracture surface of a sample tested to $2.0 \mathrm{~mm}$ of cross-head displacement are provided in Figures 6b-d. Fracture occurs through laminae containing raster lines that are oriented either into or across the plane of fracture $\left(0 / 90^{\circ}\right.$ rasters $)$. In the lowest magnification SEM micrograph (Fig. 6b), differentiation of the laminae is possible through identification of macro-porous regions which are typically 10 s of micrometers in void width. Macro-scale porosity is common for additively manufactured parts and is a result of incomplete weld-line overlap during printing on an inter-laminar (between each layer) and an intra-laminar (between raster lines in each layer) level. The origin of crack propagation is also apparent as a line across the width of the image. This line is a result of the razor blade indentation made during the pre-cracking process. A higher magnification image of the fracture region is provided in Figure 6c. At this scale, hackle marks through fractured material are visible and show the direction of crack propagation (from bottom to top). At the highest magnification (Fig. 6d), circular micro-porous regions of ca. $3 \mu \mathrm{m}$ in diameter are apparent and are a result of the rubber particle cavitation process during failure [7-9]. 


\subsection{Fracture testing of samples with oblique lamina/crack-tip orientations}

A load vs. displacement curve for a sample with $\theta=75^{\circ}$ is provided in Figure 7 a alongside images of the material during and after testing in Figures 7b-f. Elastic loading is observed initially (Fig. 7b), however, elastic-plastic fracture through laminae (cross-laminar fracture) ensues after approximately $0.6 \mathrm{~mm}$ of cross-head displacement as indicated by non-linarites in the load vs. displacement curve, as well as observable whitening (crazing) ahead of the crack-tip (Fig. 7c). Eventually, crack propagation reaches an inter-laminar region where it deviates from co-planarity with the initial pre-crack and kinks toward a region of lower toughness to propagate between laminae as depicted in Figures 7d-f. Multiple kinking events occur until crack propagation becomes solely inter-laminar.

\section{Discussion}

\subsection{Comparison of cross-laminar and inter-laminar fracture}

Representative load vs. displacement curves for vertically printed $\left(\theta=0^{\circ}\right)$ and horizontally printed $\left(\theta=90^{\circ}\right)$ samples are provided in Figure 8a. Significantly more energy was required to initiate cross-laminar fracture $\left(\theta=90^{\circ}, J_{I c}=2260 \mathrm{~J} / \mathrm{m}^{2}\right)$ than inter-laminar fracture $\left(\theta=0^{\circ}, J_{I c}=256 \mathrm{~J} / \mathrm{m}^{2}\right)$. This comparison is reflected in the load vs. displacement curve, as low-energy brittle failure occurs during inter-laminar fracture, while high-energy ductile tearing occurs for cross-laminar fracture. We hypothesize that this difference in fracture resistance is due primarily to the low inter-laminar bond strength that results from incomplete polymer melt diffusion as hot polymer is deposited onto the cooler, solidified polymer part.

The measured cross-laminar elastic-plastic critical strain energy release rate $\left(J_{I c}=2260 \mathrm{~J} / \mathrm{m}^{2}\right)$ is less than, but comparable to, $J_{I c}$ values of injection molded ABS SENB samples (between 3,600 and $5,900 \mathrm{~J} / \mathrm{m}^{2}$ ) previously tested by Lu et al [32]. Lower $J_{I c}$ values in our work are likely a result of porosity in the sample from the FFF process. Porosity reduces the volume of the sample through which the crack 
must propagate, resulting in more crack propagation (and lower values of $J$ ) in the AM part than one would expect in a fully dense part.

\subsection{Kinked fracture behavior in oblique specimens}

Representative load vs. displacement curves for obliquely printed $\left(\theta=75^{\circ}\right)$ samples are compared to vertically and horizontally printed samples in Figure 8a. Although critical elastic-plastic strain energy release rate values for specimens with oblique raster/crack-tip orientations are not reported, energy under the load vs. displacement curve for oblique samples was higher than those of vertically printed samples (inter-laminar fracture) and lower than those of horizontally printed samples (cross-laminar fracture) for approximately the same crack propagation length. From this information, we infer that $J_{I c}$ for crack initiation in samples with an arbitrary crack-tip/laminae orientation falls somewhere between that of interlaminar fracture $\left(\theta=0^{\circ}, J_{I c}=256 \mathrm{~J} / \mathrm{m}^{2}\right)$ and cross-laminar fracture $\left(\theta=90^{\circ}, J_{I c}=2260 \mathrm{~J} / \mathrm{m}^{2}\right)$.

As the laminae orientation deviates from perpendicular $\left(\theta \approx 90^{\circ}\right)$ to parallel $\left(\theta \approx 0^{\circ}\right)$ to the crack plane in a SENB specimen, propensity for crack kinking and inter-laminar fracture increases. In addition, Figure $7 \mathrm{f}$ shows that, for $\theta=75^{\circ}$, the crack exhibits a mixture of cross-laminar and inter-laminar fracture. Therefore, as the laminae angle is swept from $\theta=0^{\circ}$ to $\theta=90^{\circ}$, three distinct orientation ranges ensue which dictate material response. From $0^{\circ}<\theta<\theta_{1}$, fracture is primarily inter-laminar (Fig. 8b); from $\theta_{1}<$ $\theta<\theta_{2}$, the crack exhibits a mixture of cross-laminar and inter-laminar failure (Fig. 8c); and from $\theta_{2}<\theta<$ $90^{\circ}$, the crack travels in a predominantly cross-laminar manner (Fig. 8d). The present data suggests that

$0^{\circ}<\theta_{1}<75^{\circ}$ and $75^{\circ}<\theta_{2}<90^{\circ}$ for our material system. The critical angles to induce crack kinking behavior may be explored further using advanced orthotropic fracture theory [38], but is left for future work.

\subsection{Discussion of orthotropic fracture behavior with biological analogies}


Our results indicate that $J_{I c}$ for inter-laminar fracture $\left(256 \mathrm{~J} / \mathrm{m}^{2}\right)$ is nearly an order of magnitude lower than $J_{I c}$ for cross-laminar fracture $\left(2260 \mathrm{~J} / \mathrm{m}^{2}\right)$ for FFF ABS parts. Orthotropic fracture properties of this type are common in biological materials like nacre, dentin, wood, and bone [38-43]. Human long bones have Haversian canals and associated lamellar structures which span the length of the bone and provide toughening mechanisms for cracks propagating across the width of the bone. In one example, osteotic SENB samples were loaded in pure mode I with a pre-crack notch perpendicular to the Haversian canals. Crack propagation was not co-planar with the direction of the pre-crack notch, but instead deviated to follow perpendicularly oriented Haversian canal structures [42]. This behavior was explained by the competition between the line of maximum strain energy ahead of the crack-tip $\left(\boldsymbol{G}_{\max }\right)$ and gradients of toughness in the orthotropic material along lines misoriented with respect to $\boldsymbol{G}_{\max }$. Cracks prefer to propagate between longitudinally oriented Haversian canals in an inter-laminar fashion and kink away from lines of $\boldsymbol{G}_{\max }$. Similarly in wood, crack propagation generally occurs along the fibers, irrespective of both the original crack orientation and the degree of mode mixity [40, 41]. Analogous to bone and wood, AM ABS materials exhibit orthotropic fracture behavior with low inter-laminar toughness and high crosslaminar toughness. Because of this orthotropic behavior, we have observed crack kinking during fracture tests of samples with oblique crack-tip lamina orientations. The presence of mixed fracture modes suggests that it may be possible to enhance fracture tolerance or enforce predictable failure in FFF components by tailoring laminate orientation and inter-laminar properties in a biologically-inspired manner.

Natural materials employ other techniques to improve inter-laminar fracture properties which we may also consider when fabricating additively manufactured parts. At the nanoscale, bones utilize a nonfibrillar organic matrix of high toughness which acts as a glue to hold mineralized fibrils together, significantly increasing toughness [44]. An AM part consisting of tough, fine-scale interleaves between laminae or fine scale chopped fibers to enact inter-laminar fiber-bridging may provide significantly more inter-laminar toughness and overall durability to the AM part. 


\subsection{Potential strategies for enhanced energy absorption in AM structures}

Fracture analysis seeks to determine critical loading and stress levels that cause initiation and propagation of a crack from an initial pre-crack. This information is traditionally used to design structures to resist fracture, i.e. enforce factors of safety to ensure that flaws in the structure do not induce catastrophic failure. Fracture testing and analysis as performed in the present study can be applied to such engineering design problems to predict the onset of fracture in stressed AM structures.

In addition to traditional safety factors, fracture initiation is relevant to the creation of energy absorbing structures. For example, automotive crush zones and ballistic barriers rely on widespread, engineered deformation and damage to absorb impact energy and minimize stress and energy transfer. We hypothesize that the high density of interfaces in AM parts, combined with the ability to intricately tailor the density, orientation, and transitional gradients of such interfaces, could be exploited to create AM parts with highly tuned and efficient energy absorption behaviors. The oblique sample demonstrates that a single initial pre-crack can transform into multiple inter-laminar and intra-laminar fracture surfaces due to competing stress fields and structural gradients. Furthermore, the ability of processes like FFF to deposit multiple materials under locally tailored bonding conditions provides further opportunity to create topologically complex failure processes. Demonstration of these principles in energy absorbing AM structures will be addressed in a future study.

\section{Conclusions}

In this paper, single edge notch bend testing of additively manufactured poly(acrylonitrilebutadiene-styrene) materials was executed. Crack-tip/lamina orientation angles were varied to investigate the orthotropic nature of the AM materials. Results demonstrated that the critical elastic-plastic strain energy release rate, $J_{I c}$, required to propagate cracks across the laminae (cross-laminar fracture) was approximately an order of magnitude greater than energy required to propagate cracks between laminae 
(inter-laminar fracture). Brittle behavior was observed during inter-laminar fracture while ductile response was observed for cross-laminar fracture indicating that the elastic-plastic response of the material depends on the crack-tip/lamina orientation. For samples with oblique crack-tip/laminae orientation angles, crack kinking occurred to follow weak inter-laminar weld-lines when constructed with a crack-tip/laminae orientation angle of $75^{\circ}$.

This study confirms that the low strength of weld-lines between or among laminae, relative to within a deposited polymer trace, limits the toughness of the overall part. However, the likelihood of catastrophic failure due to fracture in an AM structure can be reduced by considering anticipated stress fields when designing laminae orientations. Naturally orthotropic materials such as wood, bone, and nacre, have all adapted to capitalize on the increased toughness afforded by flaw/laminae alignment to impart global toughness in spite of constituents which may be individually brittle. We believe that there exists considerable opportunity to engineer higher performance AM parts by exploiting these design principles to create tailored fracture and failure behaviors.

\section{Acknowledgements}

This research was supported in part by an appointment to the Postgraduate Research Participation Program at the U.S. Army Research Laboratory administered by the Oak Ridge Institute for Science and Education through an interagency agreement between the U.S. Department of Energy and USARL. Authors gratefully acknowledge Mr. David Gray for his assistance with mechanical testing. 


\section{Tables}

Table 1. Summary of results for cross-laminar fracture testing.

\begin{tabular}{ccccc} 
Sample & $\begin{array}{c}\text { Cross-head Displacement } \\
\boldsymbol{\delta}(\mathbf{m m})\end{array}$ & $\begin{array}{c}\text { Crack Propagation } \\
\boldsymbol{\Delta} \boldsymbol{a}(\mathbf{m m})\end{array}$ & $\begin{array}{c}\text { Energy } \\
\mathbf{U}(\mathbf{m})\end{array}$ & $\begin{array}{c}\text { Toughness } \\
\mathbf{J}\left(\mathbf{J} / \mathbf{m}^{2}\right)\end{array}$ \\
\hline \hline 1 & 1 & 0.32 & 134 & 2.41 \\
\hline 2 & 1.2 & 0.45 & 179 & 3.44 \\
\hline 3 & 1.2 & 0.35 & 196 & 3.70 \\
\hline 4 & 1.4 & 0.92 & 247 & 4.47 \\
\hline 5 & 1.4 & 0.52 & 235 & 4.58 \\
\hline 6 & 1.6 & 0.82 & 336 & 6.35 \\
\hline 7 & 1.6 & 0.93 & 338 & 6.39 \\
\hline 8 & 1.8 & 1.44 & 425 & 7.90 \\
\hline 9 & 1.8 & 1.12 & 415 & 7.84 \\
\hline 10 & 2 & 1.94 & 484 & 8.80 \\
\hline 11 & 2.2 & 1.76 & 553 & 10.47 \\
\hline
\end{tabular}




\section{Figures}

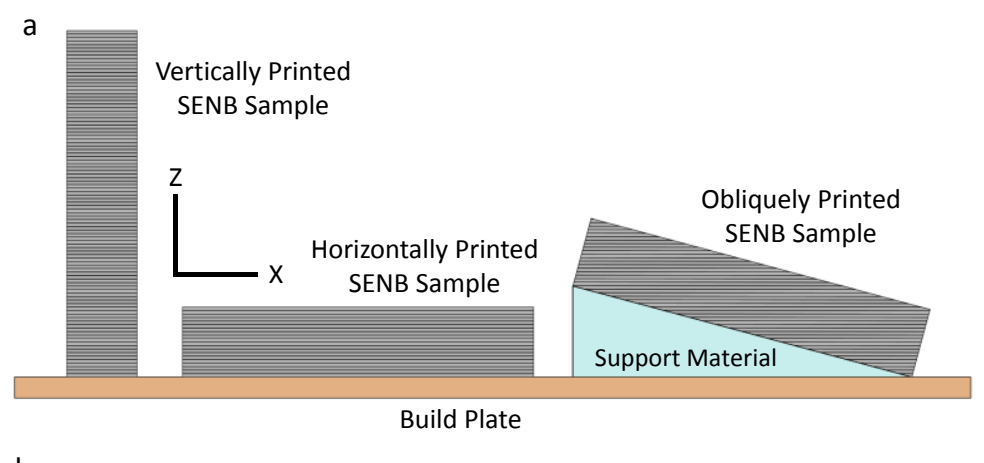

b

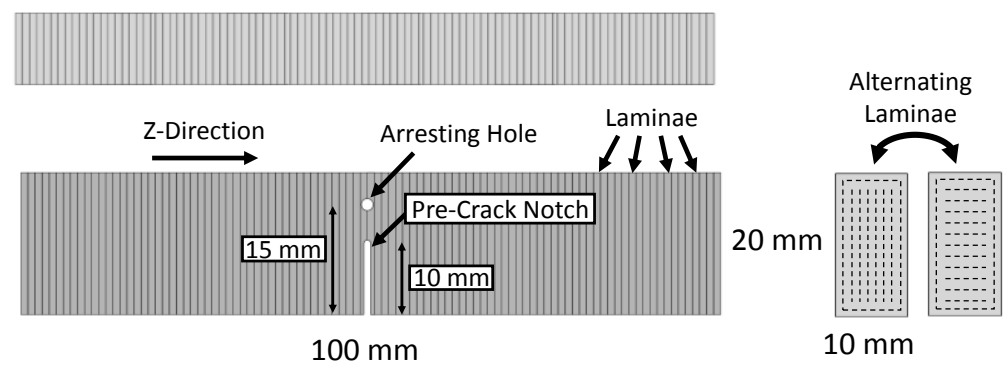

c

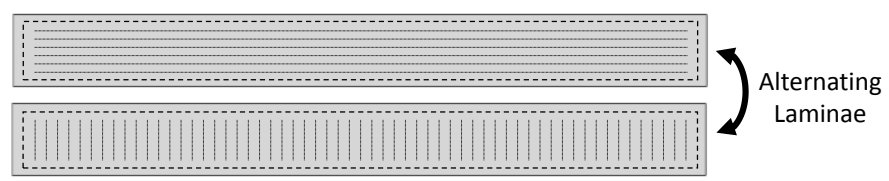

Z-Direction $\uparrow$
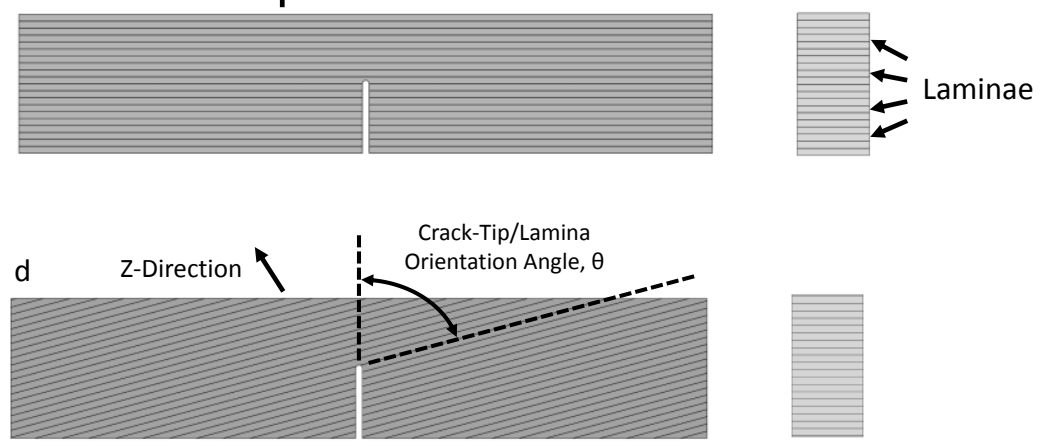

Figure 1. Illustrations of SENB fracture specimens. (a) Orientation of vertically, horizontally, and obliquely printed SENB pre-cursors with respect to the build plate. (b) Dimensions of a vertically printed SENB sample after removal from the build plate, preparation of the pre-crack, and machining of the arresting hole. Here the laminae run parallel to the pre-crack, facilitating inter-laminar fracture. (c) Illustration of a horizontally printed SENB sample after removal from the build plate and preparation of 
the pre-crack. Here the laminae run perpendicular to the pre-crack, facilitating cross-laminar fracture. (d) Illustration of an obliquely printed SENB sample after removal from the build plate and preparation of the pre-crack. Laminae are oriented at an angle of $\theta$ with respect to the pre-crack notch. Laminae, pre-crack notches, and raster lines are not to scale. Dashed lines indicate position and orientation of weld-lines (not to scale) between deposition traces within each laminae. 


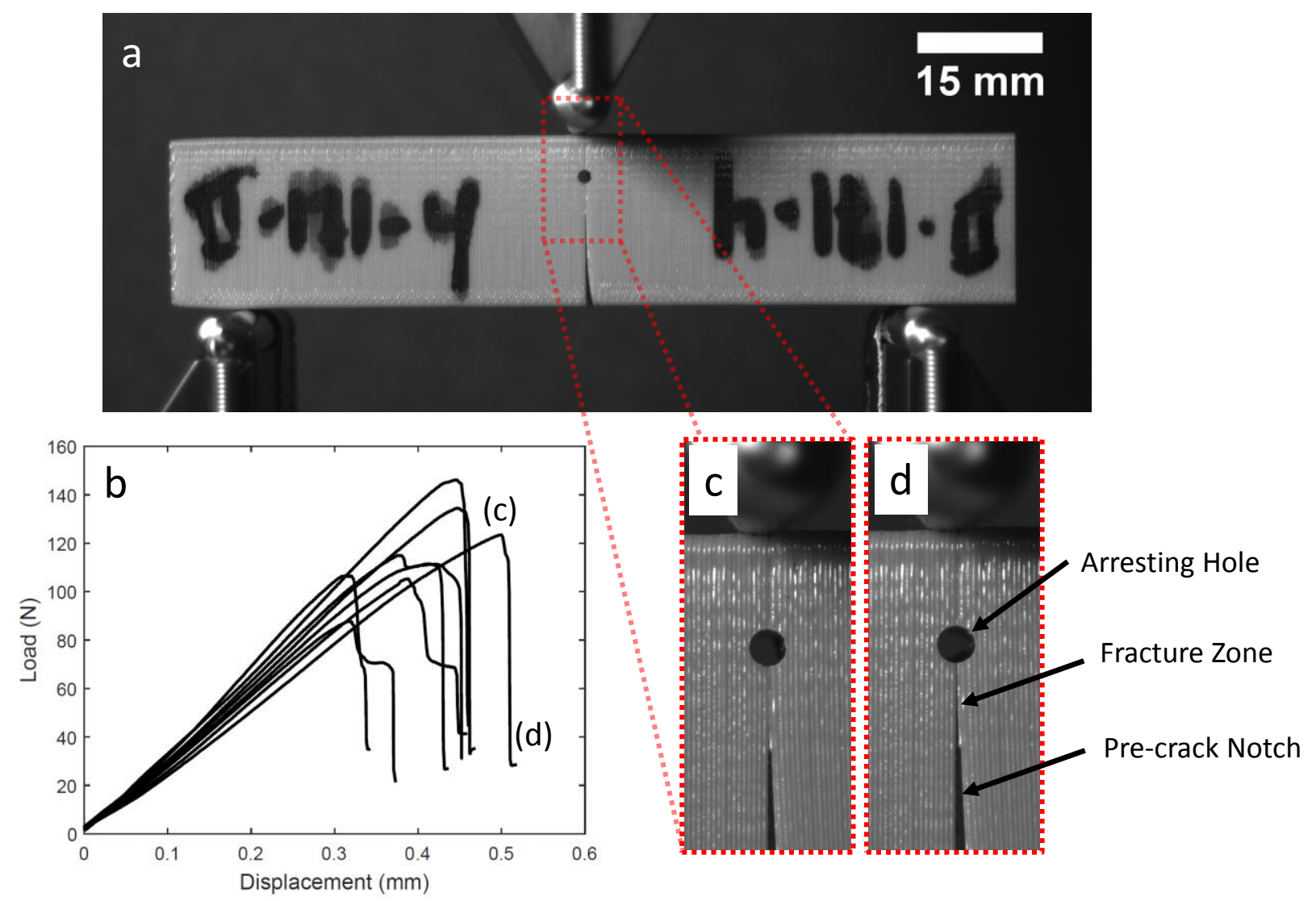

Figure 2. Inter-laminar fracture testing. (a) SENB sample in preparation for inter-laminar fracture testing. (b) Load vs. displacement curve for multiple SENB samples. Letters in parentheses indicate approximate load and displacement values of the sample as it is depicted in (c) and (d). (c) Images of the crack-tip immediately prior to fracture. (d) Image of the crack-tip immediately following fracture. 

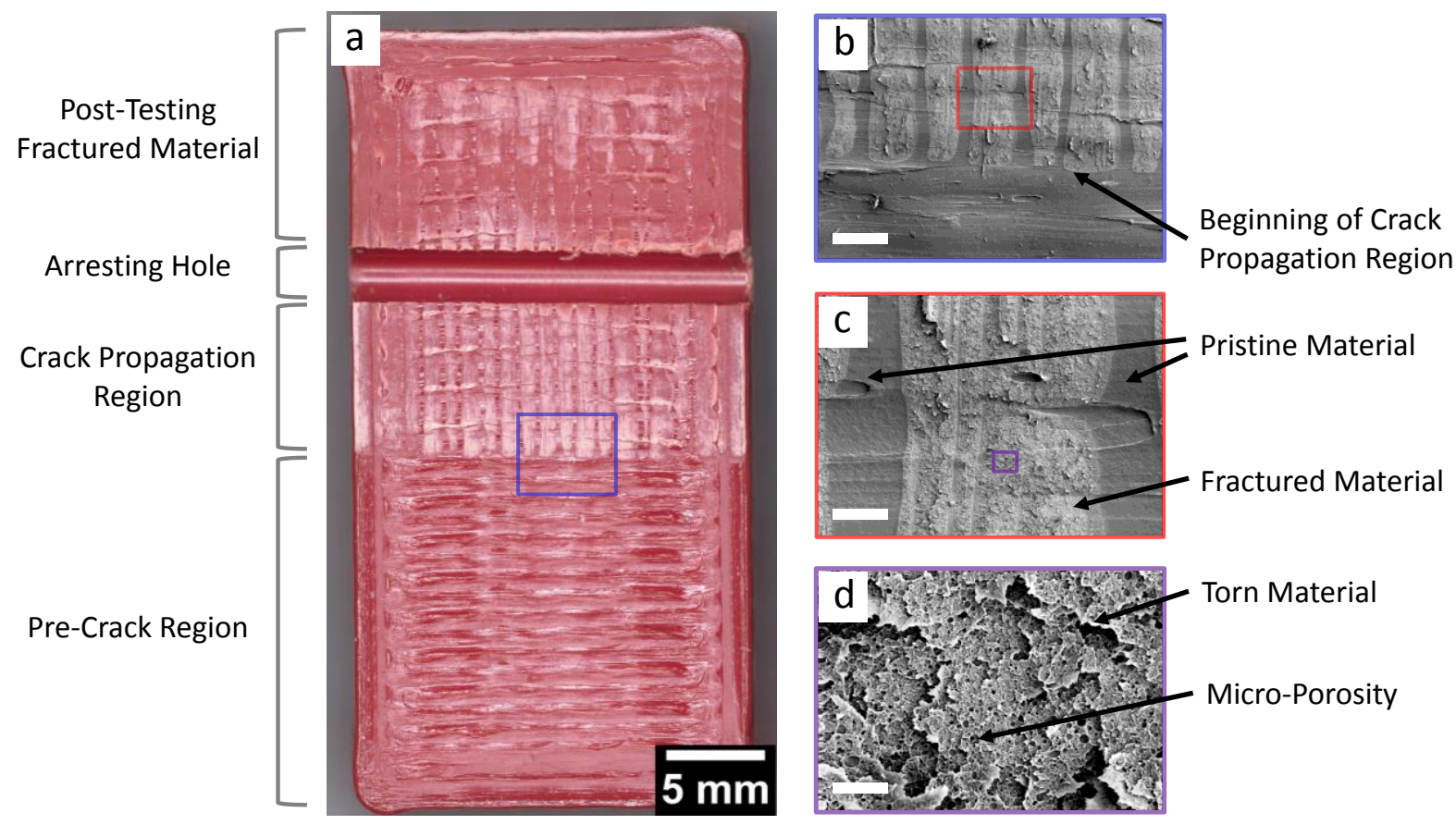

Figure 3. (a) Optical micrograph of the fracture surface of a vertically printed SENB sample following inter-laminar fracture testing. (b) SEM micrograph of the fracture surface in the vicinity of the pre-crack notch tip highlighted by the blue box in (a). Scale bar is $500 \mu \mathrm{m}$. (c) SEM micrograph of the fracture surface of a single raster line highlighted by the red box in (b). Scale bar is $100 \mu \mathrm{m}$. (d) SEM micrograph of the fracture plane morphology highlighted by the purple box of (c). Scale bar is $10 \mu \mathrm{m}$. Crack propagation was from bottom to top in all images. 


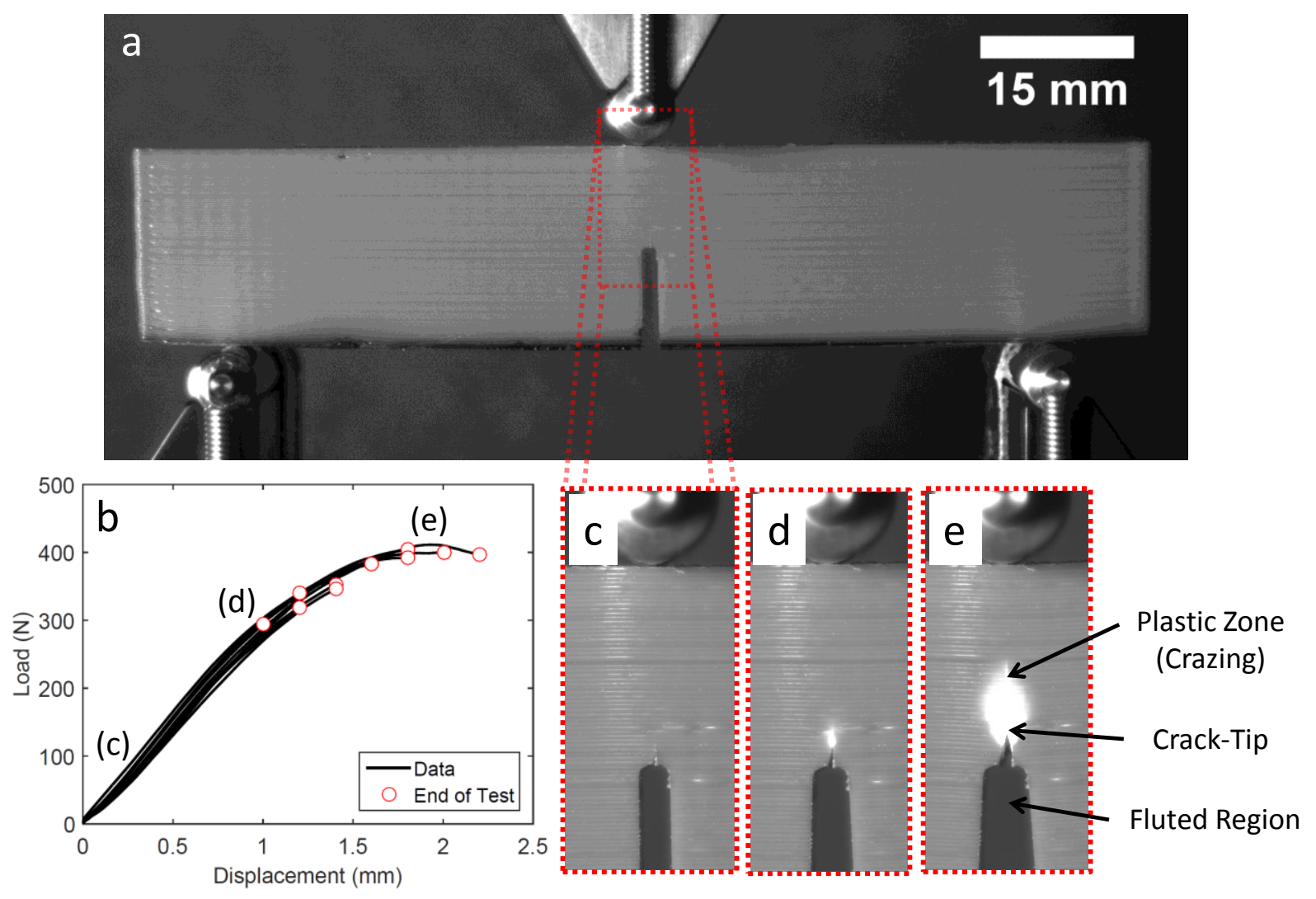

Figure 4. Cross-laminar fracture testing. (a) SENB sample in preparation for cross-laminar fracture testing. (b) Load vs. displacement curves for multiple SENB samples tested to cross-head displacement values ranging from 1 to $2.2 \mathrm{~mm}$. Letters in parentheses indicate approximate load and displacement values of the sample as it is depicted in (c), (d), and (e). (c) Images of the crack-tip region at $0.2 \mathrm{~mm}$ of displacement. (d) Image of the crack-tip region at approximately $1 \mathrm{~mm}$ of displacement. (e) Image of the crack-tip region at approximately $2 \mathrm{~mm}$ of cross-head displacement with the plastic zone, crack-tip, and fluted region annotated. 


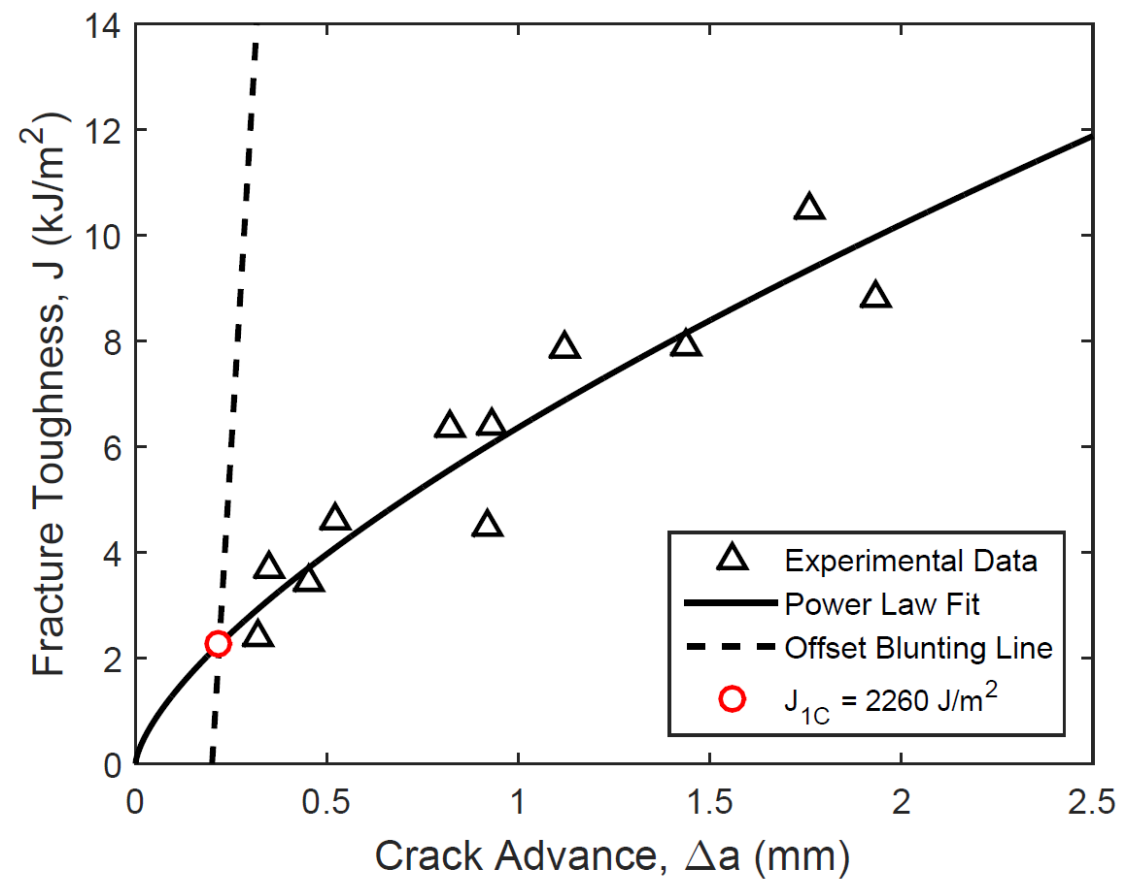

Figure 5. J-R curve for SENB specimens tested in the cross-laminar orientation $\left(\theta=90^{\circ}\right)$. 


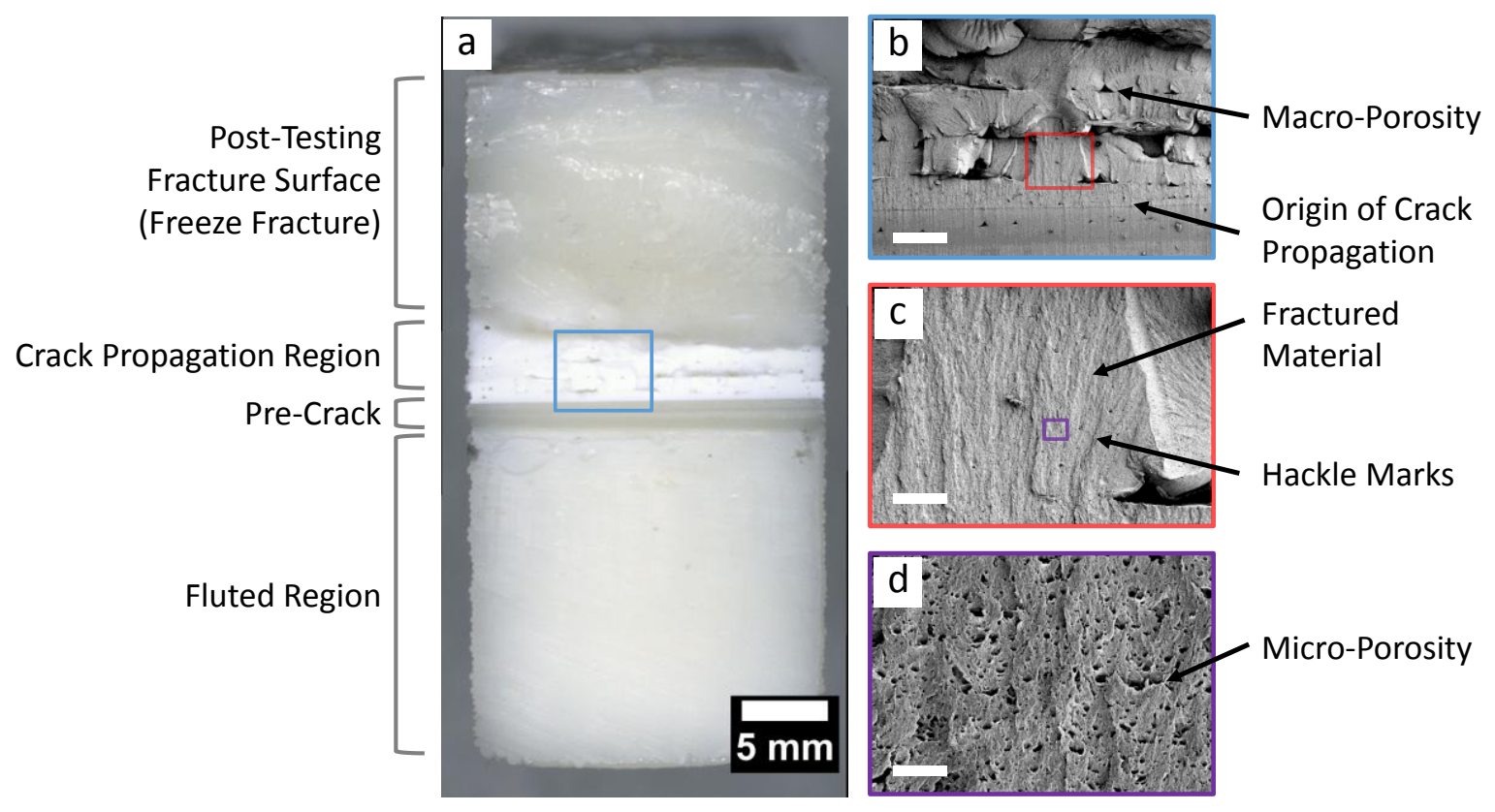

Figure 6. (a) Optical micrograph of the fracture surface of a SENB sample following cross-laminar fracture testing. (b) SEM micrograph of the fracture surface in the vicinity of the pre-crack notch tip highlighted by the blue box in (a). Scale bar is $500 \mu \mathrm{m}$. (c) SEM micrograph of the fracture surface highlighted by the red box in (b). Scale bar is $100 \mu \mathrm{m}$. (d) SEM micrograph of the fracture plane morphology highlighted by the purple box of (c). Scale bar is $10 \mu \mathrm{m}$. Crack propagation is from bottom to top in all images. 

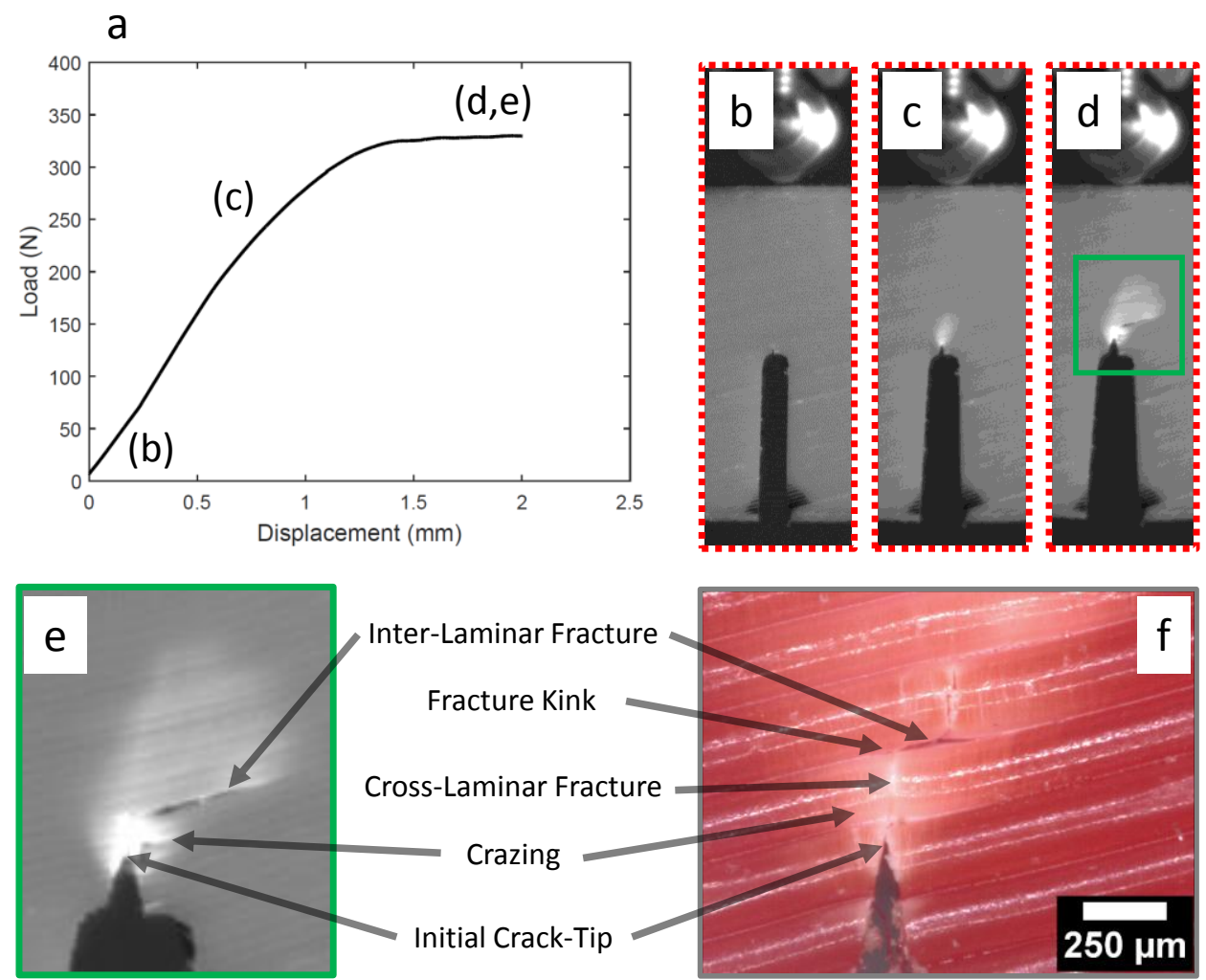

Figure 7. Oblique SENB fracture testing. (a) Load vs. displacement curve for a single sample. (b) Image of the crack-tip region in an unloaded configuration. (c) Image of crack-tip after approximately 1 $\mathrm{mm}$ of cross-head displacement. (d) Image of the crack-tip at approximately $2 \mathrm{~mm}$ of cross-head displacement. (e) Image of fractured material ahead of the crack-tip after approximately $2.0 \mathrm{~mm}$ of cross-head displacement. (f) Optical micrograph of fractured material near the crack-tip after release of load. 


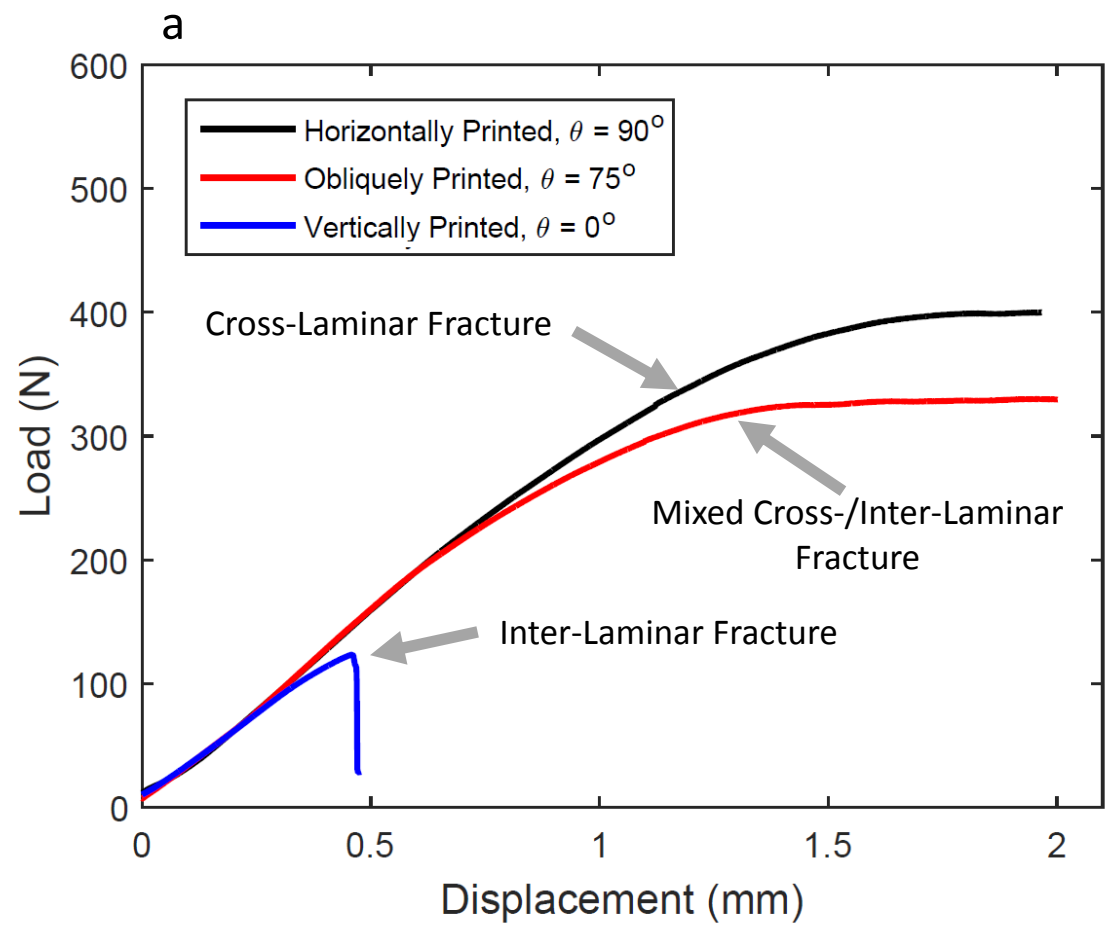

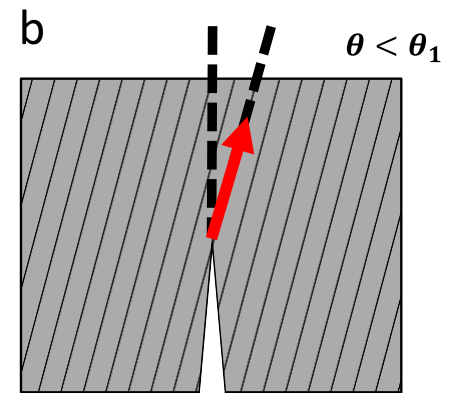

Inter-Laminar Fracture Low Toughness

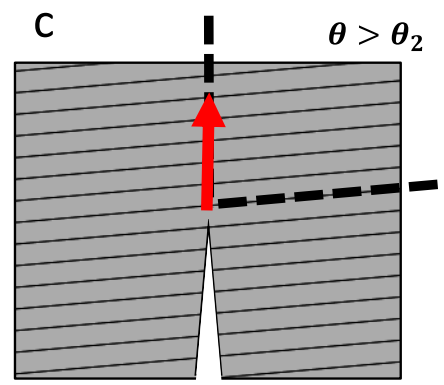

Cross-Laminar Fracture High Toughness

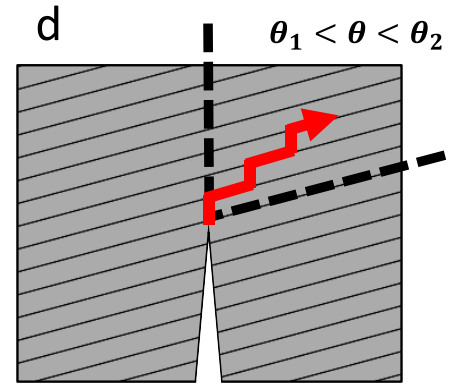

Mixed Cross-/Inter-Laminar Fracture Moderate Toughness 
Figure 8. Effect of crack-tip/lamina orientation angle, $\theta$, on the fracture response of SENB specimens. (a) Load vs. displacement curves for SENB specimens with crack-tip/lamina orientation angles of $\theta=0^{\circ}$, $\theta=75^{\circ}$, and $\theta=90^{\circ}$. Vertically printed SENB specimens with $\theta=0^{\circ}$ exhibit inter-laminar fracture, modelled by the illustration in (b). In this model, $\theta<\theta_{l}$ and crack propagation occurs between lamina at low energy costs. Horizontally printed SENB specimens with $\theta=90^{\circ}$ exhibit cross-laminar fracture, modelled by the illustration in (c). In this model, $\theta>\theta_{2}$ and crack propagation is forced through the laminar structure at high energy costs. Obliquely printed SENB specimens with $\theta=75^{\circ}$ exhibit mixed cross-/inter-laminar fracture behavior, modelled by the illustration in (d). In this model, $\theta_{1}<\theta<\theta_{2}$ causing crack kinking to occur and resulting mixed cross-/inter-laminar fracture. Red arrows depict the anticipated crack propagation path. 


\section{References}

[1] A. M. Forster, "Materials Testing Standards for Additive Manufacturing of Polymer Materials: State of the Art and Standards Applicability," National INstitute of Standards and TechnologyMay 20152015.

[2] O. Ivanova, C. Williams, and T. Campbell, "Additive manufacturing (AM) and nanotechnology: promises and challenges," Rapid Prototyping Journal, vol. 19, pp. 353364, 2013.

[3] B. N. Turner, R. Strong, and S. A. Gold, "A review of melt extrusion additive manufacturing processes: I. Process design and modeling," Rapid Prototyping Journal, vol. 20, pp. 192-204, 2014.

[4] M. D. G. Wolkowicz, S. K., "Effect of thermal aging on impact strength acrylonitrilebutadiene-styrene (ABS) Terpolymer," Polymer Engineering and Science, vol. 21, pp. 571-575, 1981.

[5] M. G. Wyzgoski, "Effects of oven aging on ABS, Poly(Acrylonitrile-Butadiene-Syrene)," Polymer Engineering and Science, vol. 16, pp. 265-269, 1976.

[6] R. S. Marissen, D.; Kemp A. V. J. M.; Coolen, S. M. H.; Duijzings, W. G.; Van Der Pol, A.; Van Gulick, A. J., "The effect of material defects on the fatigue behabiour and the fracture strain of ABS," Journal of Materials Science, vol. 36, pp. 4167-4180, 20012001.

[7] P. Y. B. Jar, T. Shinmura, and K. Konishi, "A study of rubber particle cavitation in poly(ABS) using a freeze fracture technique," Journal of Materials Science Letters, vol. 19, pp. 73-75, 2000.

[8] S. Ramaswamy and A. J. Lesser, "Microscopic damage and macroscopic yield in (ABS) resins tested under multi-axial stress states," Polymer, vol. 43, pp. 3743-3752, 2002.

[9] P. Y. B. Jar, R. Lee, T. Shinmura, and K. Konishi, "Rubber particle cavitation on toghness enhancement of SMI-modificed poly(ABS)," Journal of Polymer Science, vol. 37, pp. 1739-1748, 1999.

[10] M. Fernandez-Vicente, W. Calle, S. Ferrandiz, and A. Conejero, "Effect of Infill Parameters on Tensile Mechanical Behavior in Desktop 3D Printing," 3D Printing and Additive Manufacturing, vol. 3, pp. 183-192, 2016.

[11] D. P. Cole, J. C. Riddick, H. M. Iftekhar Jaim, K. E. Strawhecker, and N. E. Zander, "Interfacial mechanical behavior of 3D printed ABS," Journal of Applied Polymer Science, vol. 133, 2016.

[12] J. C. Riddick, M. A. Haile, R. V. Wahlde, D. P. Cole, O. Bamiduro, and T. E. Johnson, "Fractographic analysis of tensile failure of acrylonitrile-butadiene-styrene fabricated by fused deposition modeling," Additive Manufacturing, vol. 11, pp. 49-59, 2016.

[13] G. C. Onwubolu and F. Rayegani, "Characterization and Optimization of Mechanical Properties of ABS Parts Manufactured by the Fused Deposition Modelling Process," International Journal of Manufacturing Engineering, vol. 2014, pp. 1-13, 2014.

[14] S. Ziemian, M. Okwara, and C. W. Ziemian, "Tensile and fatigue behavior of layered acrylonitrile butadiene styrene," Rapid Prototyping Journal, vol. 21, pp. 270-278, 2015. 
[15] A. K. Sood, R. K. Ohdar, and S. S. Mahapatra, "Parametric appraisal of mechanical property of fused deposition modelling processed parts," Materials \& Design, vol. 31, pp. 287-295, 2010.

[16] O. S. Es-Said, J. Foyos, R. Noorani, M. Mendelson, R. Marloth, and B. A. Pregger, "Effect of Layer Orientation on Mechanical Properties of Rapid Prototyped Samples," Materials and Manufacturing Processes, vol. 15, pp. 107-122, 2000.

[17] J. F. Rodríguez, J. P. Thomas, and J. E. Renaud, "Mechanical behavior of acrylonitrile butadiene styrene (ABS) fused deposition materials. Experimental investigation," Rapid Prototyping Journal, vol. 7, pp. 148-158, 2001.

[18] J. F. Rodriguez, "Modeling the mechanical behavior of fused deposition ABS polymer components," Aerospace \& Mechanical Engineering Department, University of Notre Dame, Notre Dame, IN, 1999.

[19] Q. Sun, G. M. Rizvi, C. T. Bellehumeur, and P. Gu, "Effect of processing conditions on the bonding quality of FDM polymer filaments," Rapid Prototyping Journal, vol. 14, pp. 7280, 2008.

[20] A. Vairis, M. Petousis, N. Vidakis, and K. Savvakis, "On the Strain Rate Sensitivity of Abs and Abs Plus Fused Deposition Modeling Parts," Journal of Materials Engineering and Performance, vol. 25, pp. 3558-3565, 2016.

[21] A. K. Sood, R. K. Ohdar, and S. S. Mahapatra, "Experimental investigation and empirical modelling of FDM process for compressive strength improvement," Journal of Advanced Research, vol. 3, pp. 81-90, 2012.

[22] G. L. Percoco, F.; Galantucci, L. M., "Compressive Properties of FDM Rapid Prototypes Treated with a Low Cost Chemical Finishing," Journal of Applied Sciences, Engineering and Technology, vol. 4, pp. 3838-3842, October 1, 20122012.

[23] J. F. Rodriguez, J. P. Thomas, and J. E. Renaud, "Characterization of the mesostructure of fused-deposition acrylonitrile-butadiene-styrene materials," Rapid Prototyping Journal, vol. 6, pp. 175-186, 2000.

[24] J. F. T. Rodriguez, J. P. ; Renaud, J. E., "Maximizing the strength of fused-deposition ABS plastic parts," presented at the 10th Solid Free-form Fabrication Symposium Proceedings, Austin, TX, 1999.

[25] M. Blattmeier, G. Witt, J. Wortberg, J. Eggert, and J. Toepker, "Influence of surface characteristics on fatigue behaviour of laser sintered plastics," Rapid Prototyping Journal, vol. 18, pp. 161-171, 2012.

[26] J. Torres, M. Cole, A. Owji, Z. DeMastry, and A. P. Gordon, "An approach for mechanical property optimization of fused deposition modeling with polylactic acid via design of experiments," Rapid Prototyping Journal, vol. 22, pp. 387-404, 2016.

[27] ISO, "ISO 13586:2000 Plastics - Determination of fracture toughness (GIC and KIC) Linear elastic fracture mechanics (LEFM) approach," ed, 2000.

[28] ASTM, "ASTM E1820-15a - Standard Test Method or Measurement of Fracture Toughness," ed, 2015.

[29] ASTM, "ASTM D6068-10 - Standard Test Method for Determining J-R Curves of Plastic Materials," ed, 2010. 
[30] C. R. C. Bernal, A. N.; Frontini, P. M., "A simple method for J-R Curve Determination in ABS Polymers," Polymer Testing, vol. 14, pp. 85-96, April 19941994.

[31] C. R. F. Bernal, P. M., "Fracture Toughness Determination of ABS Polymers Using JMethod," Polymer Testing, vol. 11, pp. 271-288, October 19911992.

[32] M.-L. L. Lu, C-B.; Chang, F-C., "Fracture Toughness of Acrtlonitrile-Butadiene-Styrene by J-integral Methods," Polymer Engineering and Science, vol. 35, pp. 1433-1439, Sept 1995 1995.

[33] "ABS M30 Data Sheet," ed: Stratasys, Ltd., 2013.

[34] D. D. Dugdale, "Yielding of steel sheets containing slits," J. Mech. Phys. Solids, vol. 8, pp. 100-104, November 19591959.

[35] G. I. Barenblatt, "The Mathematical Theory of Equilibrium Cracks in Brittle Fracture," vol. 7, pp. 55-129, 1962.

[36] J. Rice, "A path in dependent integral and the approximate analysis of strain concentration by notches and cracks," Journal of Applied Mechanics, vol. 35, pp. 379386, 6/1/68 1968.

[37] E. N. Brown, "Use of the tapered double-cantilever beam geometry for fracture toughness measurements and its application to the quantification of self-healing," The Journal of Strain Analysis for Engineering Design, vol. 46, pp. 167-186, 2011.

[38] S. Bechtle, T. Fett, G. Rizzi, S. Habelitz, and G. A. Schneider, "Mixed-mode stress intensity factors for kink cracks with finite kink length loaded in tension and bending: application to dentin and enamel," J Mech Behav Biomed Mater, vol. 3, pp. 303-12, May 2010.

[39] J. Yan, J. J. Mecholsky, Jr., and K. B. Clifton, "How tough is bone? Application of elasticplastic fracture mechanics to bone," Bone, vol. 40, pp. 479-84, Feb 2007.

[40] L. O. Jernkvist, "Fracture of wood under mixed mode loading II. Experimental investigation of picea abies," Engineering Fracture Mechanics, vol. 68, pp. 565-576, November 20002000.

[41] L. O. Jernkvist, "Fracture of wood under mixed mode loading I. Derivation of fracture criteria," Engineering Fracture Mechanics, vol. 68, pp. 549-563, November 20002001.

[42] E. A. Zimmermann, M. E. Launey, H. D. Barth, and R. O. Ritchie, "Mixed-mode fracture of human cortical bone," Biomaterials, vol. 30, pp. 5877-84, Oct 2009.

[43] R. Wang and H. S. Gupta, "Deformation and Fracture Mechanisms of Bone and Nacre," Annual Review of Materials Research, vol. 41, pp. 41-73, 2011.

[44] G. E. Fantner, T. Hassenkam, J. H. Kindt, J. C. Weaver, H. Birkedal, L. Pechenik, et al., "Sacrificial bonds and hidden length dissipate energy as mineralized fibrils separate during bone fracture," Nat Mater, vol. 4, pp. 612-6, Aug 2005. 